\title{
CRIANÇAS E ADOLESCENTES NO BRASIL: A BUSCA PELA VISIBILIDADE.
}

\author{
Angela Viana Machado Fernandes ${ }^{1}$
}

\begin{abstract}
RESUMO
O objetivo deste trabalho é analisar o contexto em que crianças e adolescentes vivem hoje no Brasil. As pesquisas nos órgãos governamentais e não governamentais como as ONGs demonstram os índices de violência pelo qual são acometidos as crianças e adolescentes no país. A implantação do Estatuto da Criança e do Adolescente-ECA, em 1990 veio assegurar os direitos destes, entretanto o legislativo fica, muitas vezes, submetido ao judiciário.Concluise que políticas que resgatem os direitos, entre eles a educação formal e não formal, serão fundamentais no enfrentamento desta problemática para que, de fato, possamos afirmar que vivemos em um Estado democrático de direito.
\end{abstract}

Palavras-chave: Crianças e adolescentes. Educação. Direitos humanos.

A necessidade de assegurar os direitos voltados à criança e ao adolescente em uma sociedade desigual e injusta como a brasileira torna-se imediata. A denúncia sobre práticas brutais cometidas contra os segmentos mais pobres da população não tem tido conseqüências suficientes o que acaba por legitimar a omissão de alguns, o medo de outros quanto a medidas alternativas que possam de fato, propor políticas públicas que respeitem as necessidades locais.

O neoliberalismo cujo modelo das privatizações adotado na América Latina e no Brasil como modernizador, e a Globalização excludente com seu desemprego estrutural veio aumentar a diferença entre ricos e pobres tornando o conceito de democracia e cidadania inócuos em uma sociedade que se esvazia na privatização de suas instituições e na indiferença a fatos que tornam as crianças e jovens que vivem na pobreza, nas ruas, no narcotráfico, e na prostituição ainda mais invisíveis.

SANTOS (2006), ao analisar as diversas formas de pobreza ou de dívida social, vivida nos países subdesenvolvidos, enfatiza que no último meio século tiveram a pobreza incluída, ou seja, uma pobreza acidental que ocorre de tempos em tempos; uma segunda denominada marginalidade, produzida pelo processo econômico da divisão do trabalho; e o terceiro tipo que é a pobreza estrutural que do ponto de vista moral e político equivale a uma dívida social. A última está diretamente ligada ao processo de globalização, é uma ação deliberada, tornando-se, portanto natural com a colaboração consciente dos governos nacionais e locais.

\footnotetext{
${ }^{1}$ Departamento de Ciências da Educação - Faculdade de Ciências e Letras -Universidade Estadual Paulista 14800-901 Araraquara SP. E-mail: angela@fclar.unesp.br.
} 
A pobreza global é produzida pelas empresas e instituições globais, as mesmas que aparecem sob a figura do Banco Mundial cujo objetivo é financiar projetos de erradicação destes excluídos. É esta pobreza que gera o trabalho infantil, a prostituição de adolescentes, o tráfico de crianças, enfim, um número grande de ações que destituem as pessoas dos direitos naturais, da dignidade humana e, portanto a ética perde seu valor.

Segundo WANDERLEY (1999: 20-21) existem conceitos que compõem o universo em que pobreza e exclusão não podem ser tomadas como sinônimos. Estes conceitos surgem de diferentes formas, é a desqualificação, a desinserção, a desafiliação, e a apartação social.

A desqualificação está relacionada ao fracasso da integração, é o individuo responsável pela não inserção. Em nosso país existem representações sociais que afirmam que o jovem não aprende, pois é malandro, preguiçoso, portanto está desqualificado a entrar no mercado de trabalho. Este conceito exige que o Estado crie políticas de inserção social.

A desinserção está associada aos valores de uma determinada sociedade, são fatores simbólicos que definem quem está fora da norma, quem não tem utilidade social. Quando um jovem oriundo da Febem-Fundação Estadual do Bem Estar do Menor, entra em uma Universidade privada, torna-se herói, escreve livro e demonstra o quanto o Estado dá oportunidades iguais, portanto, negro, pobre até podem cursar o ensino superior.

A desafiliação significa a falta de pertencimento, de vinculo social. São rupturas em relação a estados de equilíbrio anteriores, é a ausência de vínculos em estruturas que tem sentido.

E a apartação social é aquele conceito que entende o outro como um ser à parte, não apenas como um desigual, mas como um não semelhante, um ser excluído dos bens de consumo, dos serviços, da educação, etc. É um fenômeno que justifica a falta de políticas estatais, a criação de grupos de extermínio, etc.

XIBERRAS (1993:19) enfatiza que existem diferentes processos que levam a exclusão e que existem formas de exclusão visíveis e outras apenas perceptíveis, porque não excluem nem materialmente, nem simbolicamente: os excluidos estão simplesmente ausentes ou invisiveis.

É esta invisibilidade que faz com que no Brasil, muitas crianças e adolescentes, cometam atos infracionais, pois perderam sua identidade.

Na mesma linha de pensamento, BAUMAN (2004) afirma que a crise da identidade está ligada não só ao processo da Globalização, mas ao esvaziamento das instituições 
democráticas e a privatização da esfera pública. A política da identidade justifica a exclusão, portanto a idéia de pertencimento não está sólida e não é garantida para toda a vida.

O que parece estar em jogo é a idéia de direitos, ou processo de acesso à cidadania, em uma sociedade que sempre viveu a mercê de mandatários, líderes populistas e autoritários. Hoje o Estatuto da Criança e do Adolescente- ECA- promulgado em 1990 assegura alguns direitos, que nem sempre são respeitados, pois o governo das leis fica a mercê de indivíduos que defendem a lei ou não, dependendo dos interesses ali implícitos.

A Declaração Universal dos Direitos Humanos está fundamentada na dignidade humana, na igualdade dos direitos. Segundo LLOMPART (2007) os direitos contidos na Declaração podem ser agrupados em quatro categorias: os direitos de caráter pessoal (art. 3 a 11); direito dos indivíduos em relação aos grupos que toma parte e ao mundo exterior (art.12 a 17); faculdades do espírito, liberdade e direitos políticos (art.18 a 21) e direitos econômicos, sociais e culturais (art. 22 a 27).

O Brasil de hoje é considerado com alto índice de criminalidade urbana. De acordo com ADORNO (2002) seus sintomas radicam, nas prisões organizadas por dirigentes do crime organizado, como o Comando Vermelho e Terceiro Comando, no Rio de Janeiro; e o Primeiro Comando da Capital em São Paulo, responsável pelo motim de 29 grandes prisões em 2001. Latrocínios e homicídios cometidos por adolescentes aumentam diariamente, levando a população ora optar a fazer justiça pelas próprias mãos, ora aceitar ações policiais que atingem, preferencialmente jovens negros e migrantes.

O aumento da violência praticada por adolescentes reconhecidamente pobres, moradores de favelas, delineia um novo padrão nos anos 2000, a necessidade de reconhecimento social, o que deveria ser natural em um Estado democrático. Se todos são iguais perante a lei, cujos direitos fundamentais são assegurados, os jovens não necessitariam mostrar-se visíveis. Segundo ZALUAR (1997) é a idéia do "ethos do ganho a qualquer preço".

Nos anos 2000 a população de 15 a 24 anos era constituída por 34 milhões de jovens. Destes 40\% viviam em uma pobreza extrema, ou seja, possuíam uma renda per capita de meio salário mínimo por mês. Alguns estudavam e trabalhavam, outros só estudavam ou só trabalhavam. À medida que a idade avança, boa parte dos jovens abandona a escola, de 53\% dos 15 aos 17 anos, para 5\% dos 20 aos 24. (ABRAMOVAY, 2003)

Estes jovens são os responsáveis, perante a sociedade e o Estado, pelo alto índice de violência. Segundo WAISELFISZ (2002:26), no Mapa da Violência III, os homicídios foram responsáveis por $39,2 \%$ de mortes de jovens em 2000, no qual 17.762 foram assassinados. A 
partir dos dados sobre a violência juvenil, a mídia aponta a sociedade como receptora de um mal em que ela não é a responsável. A escola aparece como centro de múltiplos atos violentos pelos seus usuários. O conceito de marginalidade instala-se no ambiente escolar justificando as depredações, o uso de armas e drogas, as brigas de grupos denominados gangues, enfim ao aumento da criminalidade urbana.

O trafico de drogas ronda a escola ou faz parte dela. Os bares ficam na frente, ao lado ou na quadra seguinte, possibilitando que alunos saiam para beber, fumar etc. Em pesquisa realizada pela UNESCO em 2002, intitulada Violências nas Escolas 63\% dos alunos entrevistados dizem freqüentar esses locais e algumas vezes ficam ali e faltam as aulas. A presença de armas de fogo dentro da escola foi presenciada por $13 \%$ dos estudantes entrevistados. A falta de segurança invade a vida de cada em: professores, diretores e funcionários. $\mathrm{O}$ trafico desencadeia a briga de gangues e tumultua o ambiente escolar, pois muitos alunos participam das redes de venda de drogas.

Conforme BATISTA e EL-MOOR (2000:148/149), entre a exclusão social e o desejo de destruição está o fomento ao consumo desenfreado e inalcançável e a supervalorização da beleza do mundo dos ricos e a feiúra do mundo dos pobres. E são estes jovens, pobres, que se vêem constantemente no retrato que a sociedade fez deles, mas que odeiam. O sentimento de baixa auto-estima leva estes jovens a busca de bens materiais que sua família não lhe pode oferecer e muito menos a escola. Nesta situação se constroem os heróis bandidos. Os grupos de jovens de baixo poder aquisitivo criam regras de sociabilidade e pertencimento nas quais só faz parte aquele cujos critérios de inserção sejam superados.

Hoje, ao sujeito isolado, em seus conflitos internos nada mais resta que consumir. $\mathrm{O}$ imediatismo provocado pela tecnologia, o descartável, os objetos de desejo (tênis Reebok, calças Lewis, bonés importados, computadores cada vez mais sofisticados, jogos eletrônicos que provocam "viagens"). O velho discurso da sociedade de consumo retorna sob o falso pretexto da Globalização. O cidadão portador de direitos e deveres passa para cidadão consumidor, desde que possa comprar. E, os que não tem acesso, são violentados pela industria cultural que garante a felicidade através dos objetos de consumo, e, então, nada mais lhes resta que roubar. Compra-se educação, saúde, moradia, segurança, falsas promessas de felicidade.

Existem os jovens de lares com computadores, geladeiras, microondas, máquinas e mais máquinas, congelados, empregados, etc. E os jovens das ruas? Estes que volta e meia são levados à FEBEM- Fundação do Bem Estar do Menor (presídios para menores de 18 anos), aprendem um pouco mais sobre como lidar com a malandragem e voltam para a rua. Pois é 
nesta sociedade que cresce a cada dia o uso e abuso de drogas lícitas e ilícitas, adolescentes grávidas, escolas depredadas, briga entre gangues em um mesmo bairro, porte de armas dentro da escola etc. Hoje, no Estado de São Paulo a antiga FEBEM passa a ser denominada Fundação Casa, no intuito de amenizar as denúncias dos maus tratos e a violência contra crianças e adolescentes que dela faziam parte. Entre os anos 2004 e 2007 a sociedade brasileira assistiu a um cenário de rebeliões com diversas conseqüências aos adolescentes que participaram dos atos de barbárie. A Comissão de Direitos Humanos do Estado ao desenvolver uma sindicância do interior das unidades pode observar a tortura, em seus diversos tipos, por que passam os adolescentes infratores. Espalhados no interior e na capital de São Paulo existem 57 Fundações Casa. Segundo a legislação brasileira, são consideradas crianças as pessoas com até 12 anos incompletos e adolescentes as pessoas entre 12 e 18 anos incompletos.

A Fundação Abrinq pelos direitos da Criança e do Adolescente (www.fundabrinq.org.br), apresenta dados de que o Brasil tem hoje 61 milhões de crianças e adolescentes, sendo: 23,1 milhões de crianças entre 0 a 6 anos; 27,2 milhões de crianças e adolescentes entre 7 a 14 anos; 10,7 milhões de adolescentes entre 15 e 17 anos. A maioria das crianças e adolescentes mora nas regiões Sudeste (23,5 milhões) e Nordeste (19,2 milhões) do Brasil. As regiões Norte e Centro-Oeste têm 5,7 milhões e 4,2 milhões de crianças e adolescentes, respectivamente.

O percentual de crianças e adolescentes sobre o total da população varia de uma região para outra. No Brasil, $35,9 \%$ da população total é constituída por crianças e adolescentes. Nas regiões Norte e Nordeste, este percentual aumenta para 44,5\% e 40,1\%, respectivamente. Nas regiões Sul e Sudeste, as crianças e os adolescentes representam, respectivamente, $33,4 \%$ e $32,5 \%$ da população total.

A grande maioria das crianças e adolescentes $(77,9 \%)$ vive em áreas urbanas. Com relação à raça/etnia, a população infanto-juvenil distribui-se da seguinte forma: 31 milhões de brancos (51,2\%); 25,8 milhões de pardos (42,7\%); 3,2 milhões de negros (5,4\%); 287 mil indígenas $(0,5 \%) ; 181$ mil amarelos ou de origem asiática $(0,3 \%)$.

Em relação à situação educacional de família: 33,2\% (18,9 milhões) têm mães com pouca escolaridade (nenhuma escolaridade ou sem ter completado os quatro anos do ciclo básico); 17,4\% (9,9 milhões) têm mães que completaram os quatro anos básicos da escola; $26,8 \%$ (15,3 milhões) têm mães que cursaram entre cinco e oito anos de escola (segundo ciclo); e 22,7\% (13 milhões) têm mães que freqüentaram mais de nove anos de escola. 
Quanto a possuir ou não alguma deficiência, o relatório do Unicef mostra que cerca de 2,9 milhões ou 4,7\% das crianças e dos adolescentes de 0 a 17 anos apresentavam pelo menos uma das deficiências consideradas no Censo Demográfico 2000, do IBGE. A incapacidade ou grande dificuldade permanente de enxergar é a deficiência de maior ocorrência, atingindo 1,6 milhões de crianças e adolescentes.

$\mathrm{O}$ acesso a condições adequadas de saneamento básico possui relação direta com a saúde dos moradores, assim como a existência de bens duráveis, como geladeira/freezer, computador e telefone, são importantes indicadores das condições de vida dos indivíduos.

No que concerne ao saneamento, $17,4 \%$ das crianças e dos adolescentes vivem em domicílios sem abastecimento de água internamente no domicilio, e 18,7\% não têm acesso à rede geral de esgoto, fossa séptica ou rudimentar. Além disso, 22,4\% não possuem geladeira ou freezer, $69,4 \%$ não têm telefone e mais de $90 \%$ não possuem computador em casa.

Segundo relatório da UNICEF sobre a situação mundial da Infância 2006, as causas básicas da exclusão - pobreza extrema, governança fraca, conflitos armados, HIV/Aids, desigualdades e discriminação - têm conseqüências perniciosas além de excluir a criança do acesso a serviços essenciais. Também alimentam condições que aumentam o risco que a criança corre de ser explorada, negligenciada, vítima de tráfico e de abusos. O colapso no sistema legal, que freqüentemente acompanha conflitos armados, por exemplo, pode deixar crianças expostas à exploração ou violência sexual.

Crianças órfãs ou vulneráveis devido ao HIV/AIDS não só correm maiores riscos de ficar fora do sistema educacional, como também podem enfrentar estigmas e negligência em suas comunidades. As pessoas que praticam o tráfico de crianças não procuram suas vítimas nos subúrbios ricos, mas sim nas favelas e entre as crianças mais necessitadas.

No Brasil a taxa de natalidade cresce, principalmente em menores de 15 anos. Segundo Sant'Anna (2001:62), estima-se que anualmente ocorra um milhão de partos de adolescentes, o que corresponde a $25,79 \%$ do total de nascidos vivos em 1996 . No estado de São Paulo, em 1997 ocorreram 473 partos de menores de 14 anos e 135.639 em adolescentes entre 15 e 19 anos.

Ao ratificar a Convenção sobre os Direitos da Criança (1989), O Brasil e os demais países comprometeram-se com a proteção da criança contra danos, abusos, exploração, violência e negligência. Entretanto, para milhões de crianças, a violação de seu direito à proteção é a causa principal de sua exclusão. Marginalizadas e excluídas, crianças que sofrem violações de seu direito à proteção viram-se diante dos piores elementos da experiência adulta, ou seja, da prostituição ao trabalho sob condições perigosas. 
A criança perde sua visibilidade à medida que são privadas de cuidados por parte dos pais, ou quando enfrentam violência e abusos em seus próprios lares. Também correm o risco de se tornar menos visíveis em suas comunidades e sociedades quando não freqüentam a escola, quando são confinadas em um local de trabalho, ou quando são exploradas de alguma outra forma; quando sofrem abusos ou violência fora do ambiente familiar, ou simplesmente quando não são vistas ou tratadas como crianças.

No entanto, também podemos não enxergar a situação das crianças mesmo quando estão à nossa frente, como é o caso das crianças que vivem e trabalham nas ruas. Todas essas crianças, sem exceção, necessitam de um nível de proteção que, até o momento, o mundo evidentemente não supriu.

Crianças que não têm proteção familiar, temporária ou permanentemente, não são as únicas que deveriam receber os cuidados e a atenção especiais que os Países Partes se comprometeram a oferecer. De acordo com os Artigos 20 e 40 da Convenção sobre os Direitos da Criança, os Estados também são obrigados a proteger crianças que já estão sob seus cuidados, por exemplo, em instituições ou prisões. Neste último caso, é dever do governo preservar a dignidade e o valor de crianças que infringiram a lei. Mais uma vez, as evidências disponíveis sugerem que crianças em prisões correm risco de ser mal atendidas pelos governos.

Uma avaliação realizada pela Organização Internacional do Trabalho (OIT) revelou que crianças órfãs têm probabilidade muito maior de trabalhar em agricultura comercial, como vendedores de rua, em serviços domésticos e no comércio sexual do que crianças nãoórfãs.

Entre todas as crianças, as crianças de rua são as mais visíveis fisicamente, vivendo e trabalhando nas ruas e praças públicas de cidades em todas as partes do mundo. Entretanto, paradoxalmente, são também as mais invisíveis e, portanto, as mais difíceis de ser alcançadas por serviços vitais, como educação e cuidados e saúde, e as mais difíceis de proteger.

O termo 'crianças de rua' é problemático, uma vez que pode ser associado a um estigma. Um dos maiores problemas que essas crianças enfrentam é sua condenação pela maior parte da sociedade, como uma ameaça e uma fonte de comportamento criminoso. Mesmo assim, muitas crianças que vivem ou trabalham nas ruas adotaram o termo, considerando que lhes oferece um sentido de identidade e de pertencimento.(www.unicef.com.br).É impossível quantificar o número exato de crianças de rua, mas certamente chega a dezenas de milhões em todas as partes do mundo. É provável que esse número venha aumentando com o crescimento da população global e com a contínua e 
rápida urbanização: em 2005, a expectativa é de que seis em cada dez habitantes urbanos tenham menos de 18 anos de idade. Na verdade, todas as cidades do mundo têm crianças de rua, incluindo as maiores e mais ricas cidades dos países industrializados.

Uma vez nas ruas, as crianças tornam-se vulneráveis a todas as formas de exploração e abuso, e sua vida diária provavelmente está bem distante da infância ideal prevista na Convenção. Em alguns casos, as pessoas encarregadas de protegê-las são aquelas que cometem crimes contra elas. As crianças de rua freqüentemente encontram-se em situações de conflito com a polícia e outras autoridades, e têm sido molestadas ou espancadas por elas. São arrebanhadas e conduzidas para fora dos limites da cidade, onde são abandonadas. E são assassinadas por vigilantes em nome da 'limpeza da cidade', freqüentemente com a cumplicidade ou o descaso de autoridades locais.

A lógica poderia sugerir que crianças detidas pelo sistema judiciário criminal deveriam ser, entre todas, as mais visíveis, imediatamente acessíveis a intervenções que garantissem seu acesso a cuidados de saúde, educação e proteção. No entanto, com freqüência, as crianças em conflito com a lei realmente deixam de ser consideradas como crianças. Pelo contrário, considera-se que a transgressão observada retira dessas crianças seu direito à proteção, expondo-as a um tratamento semelhante ao dos adultos infratores ou, o que é pior, elas sofrem abusos devido à sua vulnerabilidade como crianças.

Os atos infracionais cometidos por adolescentes são um tema que preocupa toda a sociedade. Dos crimes e delitos registrados a cada ano no Brasil, 10\% são cometidos por adolescentes, os outros, por adultos. Desses, mais de $70 \%$ praticam delitos contra o patrimônio. Muitas vezes os adolescentes são mais vítimas do que autores de violência. Entre adolescentes de 15 a 19 anos, 68\% das mortes são provocadas por causas externas - acidentes de trânsito, homicídios e suicídios.O hiperdimensionamento do problema dos atos infracionais cometidos por adolescentes gera uma demanda na sociedade por medidas mais enérgicas (dados UNICEF).

Em sua $37^{\mathrm{a}}$ sessão, o Comitê sobre os Direitos da Criança levantou uma série de questões sobre os procedimentos de proteção em relação a crianças mantidas pelo sistema judiciário no Brasil, entre outros países, incluindo relatórios de tortura e morte extrajudiciais em instalações penitenciárias.

Segundo VOLPI (2005), ao analisar 4.245 crianças e adolescentes privados de liberdade em 26 estados no ano de 1996, a relação entre pobreza e trabalho infantil e de adolescentes, ou seja, 52,6\% não trabalhavam, 47,3\% trabalhavam, mas só $6,8 \%$ possuíam carteira assinada. Destes, $96,6 \%$ não concluiu o ensino fundamental, a faixa etária varia dos 
$12(1,2 \%)$ aos 18 anos (82,2\%). Os usuários de drogas contam 53\% contra 47,7\% não usuários. As ocorrências são de roubo $(33,4 \%)$, seguido de furto $(23,8 \%)$. O número de adolescentes que cometem latrocínios e homicídios cresce a cada dia.

Enfim, os dados mostram a situação de fragilidade na qual encontram-se crianças e adolescentes de baixa renda no Brasil, e um país não pode ser democrático se perpetua a invisibilidade dos jovens. Políticas públicas de visibilidade tornam-se urgentes e enquanto não acontecem, não podemos falar de educar para a cidadania, democracia e, portanto de Direitos Humanos no Brasil.

\section{REFERÊNCIAS:}

ABRAMOVAY, M. Enfrentando a violência nas escolas: um informe do Brasil. In: UNESCO. Violência na escola: América Latina e Caribe. Brasília, 2003.

ADORNO, S. Crise no Sistema de Justiça Criminal. In: Ciência e Cultura, SBPC, São Paulo, 2000.

BATISTA, A. S.; El-MOOR, P. D. Violência e Agressão. In CODO, W. (coord.). Educação: carinho e trabalho. Petrópolis: Vozes, 2000.

BRASIL. Estatuto da Criança e do Adolescente. ECA, lei nº 8.069 de 1990.

BAUMAN, Z. Identidade. Rio de Janeiro: Zahar Editores, 2005.

FUNDAÇÃO ABRINQ. Disponível em: <http:// www.fundabrinq.org.br LLOMPART, J. B.; RUIZ-GALVEZ, E. F.; PEYRÓ, A. P. G. Derechos Humanos. Publicación Universitat de Valencia, 2007.

SANT'ANNA, M. J. C. Gravidez na adolescência: um enfoque atual. In: WEINBERG, C. (org). Geração delivery. São Paulo: Sá, 2001.

SANTOS, M. Por uma outra globalização: do pensamento único à consciência universal. $13^{\mathrm{a}}$ ed., Rio de Janeiro: Record, 2006. 
SÃO PAULO. Fundação Casa. Disponível em: <http://www.casa.sp.gov.br.

UNESCO. Violência na escola: América Latina e Caribe. Brasília: UNESCO, 2003

UNICEF. Convenção sobre os Direitos da Criança. Disponível em: < http:// www.unicef.org/brasil/dir cri.

UNICEF. Declaração Universal dos Direitos Humanos. Disponível em: <http:// www.unicef.org/brasil

VOLPI, M. (org.)- O adolescente e o ato infracional. $5^{\text {a }}$ ed., São Paulo: Cortez, 2005.

WAISELISZ, J. J. Mapa da violência III: os jovens do Brasil. Brasília: UNESCO, 2003.

XIBERRAS, M. As teorias da exclusão. Para uma construção do imaginário do desvio. Lisboa: Instituto Piaget, 1993.

ZALUAR, A - Exclusão social e violência in ZALUAR, A. (org) Violência e educação. São Paulo: Cortez, 1997. 